\title{
The Role of OralID Guided Biopsy in Diagnosis of Oral Epithelial Dysplastic Lesions
}

\author{
Original Abd Elfattah A. Sadakah, Khaled Abd Elhamed Saad, Eman Mohie Eldeen \\ Article Megahed, Omnia Ali Ali El-Bahgy \\ Department of Oral and Maxillofacial Surgery, Faculty of Dentistry, Tanta University, \\ Gharbia, Egypt
}

\begin{abstract}
Statement of the problem: Many lights based noninvasive diagnostic techniques has been developed that aids in the early detection of oral cancer. Among these, autofluorescence based diagnostic techniques.

Purpose: This study designed to evaluate the diagnostic accuracy of OralID device in early diagnosis and guiding the margins of biopsy in management of suspected oral dysplastic lesions.

Materials and Methods: Randomized clinical study was carried out on twenty selected patients with suspected oral mucosal lesions were collected from the outpatient clinic of Oral and Maxillofacial Surgery Department, Faculty of Dentistry, Tanta University. Areas clinically suspicious detected by conventional oral examination (COE) or direct visual fluorescence evaluation (DVFE) were further investigated using surgical biopsy.

Results: The device showed sensitivity $100 \%$ and specificity $40 \%$.

Conclusion: The study demonstrated its usefulness for clinical examination, monitoring oral lesions but the false negative test result may limit its utility in taking a biopsy with a safety margin.
\end{abstract}

Key Words: Fluorescence, non-invasive diagnosis, oral cancer, OralID

Received: 26 December 2020, Accepted: 05 January 2021

Corresponding Author: Omnia Ali Ali El-Bahgy, Department of Oral and Maxillofacial Surgery, Faculty of Dentistry, Tanta University, Egypt, Tel.: 0201007666358,E-mail: omnia_elbahgy@yahoo.com

ISSN: 2090-097X, July 2020, Vol. 11, No. 3

\section{INTRODUCTION}

Many oral Squamous cell carcinomas are believed to develop from oral premalignant lesions, and early detection and diagnosis of these premalignant lesions should be possible. Early detection of oral cancer is believed to reduce the morbidity and increase the survival of patients. The histopathological analysis of suspected lesions is the gold standard for oral cancer diagnosis ${ }^{[1]}$.

Recent advancements in oral cancer research have led to the development of potentially useful diagnostic tools at the clinical level like OralID device which help in early detection of oral mucosal lesions especially the dysplastic ones which could be of value in screening of suspected oral mucosal lesions and for the early detection of oral cancer $^{[2]}$.

So, in this study we will evaluate the diagnostic accuracy of OralID device in early diagnosis and guiding the margins of biopsy in management of oral mucosal lesions.

The concept of a stepwise development of cancer in the oral mucosa, i.e., the initial presence of a precursor (pre-malignant/precancerous) lesion subsequently developing into cancer is well established. The presence of epithelial dysplasia may be even more important in predicting malignant development than the clinical characteristics $^{[3,4]}$.

There is a pressing need to develop new approaches that can be easily used in clinical practice to facilitate the detection of these clinically occult fields. One such new approach may involve the use of tissue optics. The association of cancer development with the loss of normal tissue autofluorescence has been reported for a number of tissues and organs ${ }^{[5,6]}$.

OralID is commercially available device used to visualize loss of tissue auto fluorescence associated with precancer and cancer in the oral cavity. OralID uses "fluorescence technology." OralID's fluorescence technology uses a blue light $(435-460 \mathrm{~nm})$ that allows a clinician to identify oral cancer, pre-cancer and other abnormal lesions at an earlier stage ${ }^{[7]}$.

OralID is a battery-operated, hand-held oral examination light used as an adjunctive device for oral 
mucosal screening. OralID is equipped with the necessary eyewear to enhance the visual effects of the blue light during the oral exam. When the blue light from OralID shines on healthy oral tissue, it fluoresces green. However, when it shines on abnormal tissue, it appears dark due to a lack of fluorescence ${ }^{[7]}$ (Figure 1).

Aim of the work: This study designed to evaluate the diagnostic accuracy of OralID device in early diagnosis and guiding the margins of biopsy in management of oral dysplastic lesions. Sensitivity and specificity values were also calculated to evaluate the validity of Direct Visual Fluorescence Examination (DVFE) in tumor margin delineation.

\section{PATIENTS AND METHODS}

Twenty patients with oral mucosal lesions were selected and biopsies were taken guided by OralID device. Patients selected from the output patient clinic of Oral and Maxillofacial Surgery Department, Tanta University.

The patients involved in this study were ( 8 males and 12 females). 6 patients at right lateral side of the tongue, 8 at left lateral side of the tongue, 2 at right check, 2 at left check, 1at lower alveolar ridge from the lower left first premolar to the lower right first premolar and 1 at the alveolar ridge at lower left molar area. The mean diameter was about $2 \mathrm{~cm}$ length $2 \mathrm{~cm}$ width.

Ethical consideration: Approval for this project was obtained from Research Ethics Committee (REC) of faculty of Dentistry, Tanta University. The purpose of the present study was explained to the patients and informed consents were obtained according to the guidelines of human research adopted by the REC at Faculty of Dentistry, Tanta University.

Inclusion Criteria: Patients with an oral mucosal lesion. Any lesion that persists for more than two weeks and sores that doesn't heal more than 3 weeks. Any inflammatory lesion not responding for treatment after 10 to 14 days following removal of identified local irritants such as trauma, infection or inflammation. The patient can also indicate whether he has matters with the tongue in chewing, speaking, or moving the jaw.

Exclusion criteria: Familial history of oral cancer prevalence. Possibility of missing follow up examination. Any systemic relevant disease.

\section{Diagnosis: Clinically:}

Oral examination performed under the dental unit light. Through extraoral examination followed by intraoral examination for lesion inspection and palpation. Evaluation of the specific characteristics of each lesion including the size, colour, texture and outline.

Histopathologically: By the preparation of slides with 4-micron thickness then hematoxylin and eosin staining. A pathologist reviewed all the slides to confirm the diagnosis and graded the presence of epithelial dysplasia at the clinical margin and the Oral ID margin.

\section{Surgical technique:}

Stage 1: Direct Visual Fluorescence Examination (DVFE) : Lesional and perilesional tissue was assessed for visual fluorescence retention and visual fluorescence loss (Figure 2).

Stage 2: Assessment of Margins by OrallD: The lesional tissue re-examined under white light and the margins of clinically apparent mucosal abnormality marked by tissue marker. These margins termed "clinical margins". The OralID examination repeated and the Visual fluororescence loss (VFL) boundary marked by tissue marker. A digital photograph of tissue markings was taken under fluorescent light (Figure 3).

Stage 3: Confirmation of margins by biopsy: Incisional or excisional biopsies according to the lesional size were taken by scalpel. The samples were obtained from the areas outside the VFL boundary by $2 \mathrm{~mm}$ in zone of Visual fluorescence retain (VFR). 
Table 1: Clinical data of the patients included

\begin{tabular}{|c|c|c|c|c|}
\hline Number & Age & Sex & Location & Lymph node affected \\
\hline 1 & 60 & Male & $\begin{array}{l}\text { Lower alveolar } \\
\text { ridge from right } \\
\quad 4 \text { to left } 4\end{array}$ & $\begin{array}{l}\text { Bilateral sub-mandibular and } \\
\text { sub-mental L.N enlarged, } \\
\text { palpable, mobile and tender }\end{array}$ \\
\hline 2 & 40 & Male & $\begin{array}{l}\text { Left lateral side } \\
\text { of tongue }\end{array}$ & $\begin{array}{l}\text { Normal palpable non } \\
\text { tender lymph nodes }\end{array}$ \\
\hline 3 & 56 & Female & $\begin{array}{l}\text { Left lateral side } \\
\text { of tongue }\end{array}$ & $\begin{array}{l}\text { Unilateral left submandibular } \\
\text { lymph nodes enlarged, } \\
\text { palpable, mobile and tender }\end{array}$ \\
\hline 4 & 50 & Male & $\begin{array}{l}\text { Left lateral side } \\
\text { of tongue }\end{array}$ & $\begin{array}{l}\text { Unilateral left submandibular } \\
\text { lymph nodes enlarged, } \\
\text { palpable, mobile and tender }\end{array}$ \\
\hline 5 & 64 & Female & Right cheek & $\begin{array}{l}\text { Unilateral right submandibular } \\
\text { lymph nodes enlarged, } \\
\text { palpable, mobile and tender }\end{array}$ \\
\hline 6 & 30 & Female & $\begin{array}{l}\text { Right lateral } \\
\text { side of tongue }\end{array}$ & $\begin{array}{l}\text { Unilateral right submandibular } \\
\text { lymph nodes enlarged, } \\
\text { palpable, mobile and tender }\end{array}$ \\
\hline 7 & 70 & Female & $\begin{array}{l}\text { Left lateral side } \\
\text { of tongue }\end{array}$ & $\begin{array}{l}\text { Unilateral left submandibular } \\
\text { lymph nodes enlarged, } \\
\text { palpable, mobile and tender }\end{array}$ \\
\hline 8 & 60 & Female & $\begin{array}{l}\text { Right lateral } \\
\text { side of tongue }\end{array}$ & $\begin{array}{l}\text { Unilateral right submandibular } \\
\text { lymph nodes enlarged, } \\
\text { palpable, mobile and tender }\end{array}$ \\
\hline 9 & 50 & Female & $\begin{array}{l}\text { Right lateral } \\
\text { side of tongue }\end{array}$ & $\begin{array}{l}\text { Unilateral right submandibular } \\
\text { lymph nodes enlarged, } \\
\text { palpable, mobile and tender }\end{array}$ \\
\hline 10 & 20 & Female & Left cheek & $\begin{array}{l}\text { Normal palpable non } \\
\text { tender lymph nodes }\end{array}$ \\
\hline 11 & 30 & Female & $\begin{array}{l}\text { Right lateral } \\
\text { side of tongue }\end{array}$ & $\begin{array}{l}\text { Unilateral right submandibular } \\
\text { lymph nodes enlarged, } \\
\text { palpable, mobile and tender }\end{array}$ \\
\hline 12 & 40 & Female & $\begin{array}{l}\text { Left lateral side } \\
\text { of tongue }\end{array}$ & $\begin{array}{l}\text { Normal palpable non } \\
\text { tender lymph nodes }\end{array}$ \\
\hline 13 & 45 & Male & Left cheek & $\begin{array}{l}\text { Normal palpable non } \\
\text { tender lymph nodes }\end{array}$ \\
\hline 14 & 55 & Male & $\begin{array}{l}\text { Right lateral } \\
\text { side of tongue }\end{array}$ & $\begin{array}{l}\text { Unilateral right submandibular } \\
\text { lymph nodes enlarged, } \\
\text { palpable, mobile and tender }\end{array}$ \\
\hline
\end{tabular}


15

16

17

18

19

20
35

Male

45

Female

Female

Male

65

70

Male

35
Right lateral

side of tongue

Left lateral side

of tongue

Right cheek

Left lateral side of tongue

Left lower

alveolar ridge

at molar area

Left lateral side of tongue
Unilateral right submandibular lymph nodes enlarged, palpable, mobile and tender

Unilateral left submandibular lymph nodes enlarged, palpable, mobile and tender

Unilateral right submandibular lymph nodes enlarged, palpable, mobile and tender

Unilateral left submandibular lymph nodes enlarged, palpable, mobile and tender

Unilateral left submandibular lymph nodes enlarged, palpable, mobile and tender

Unilateral left submandibular lymph nodes enlarged, palpable, mobile and tender

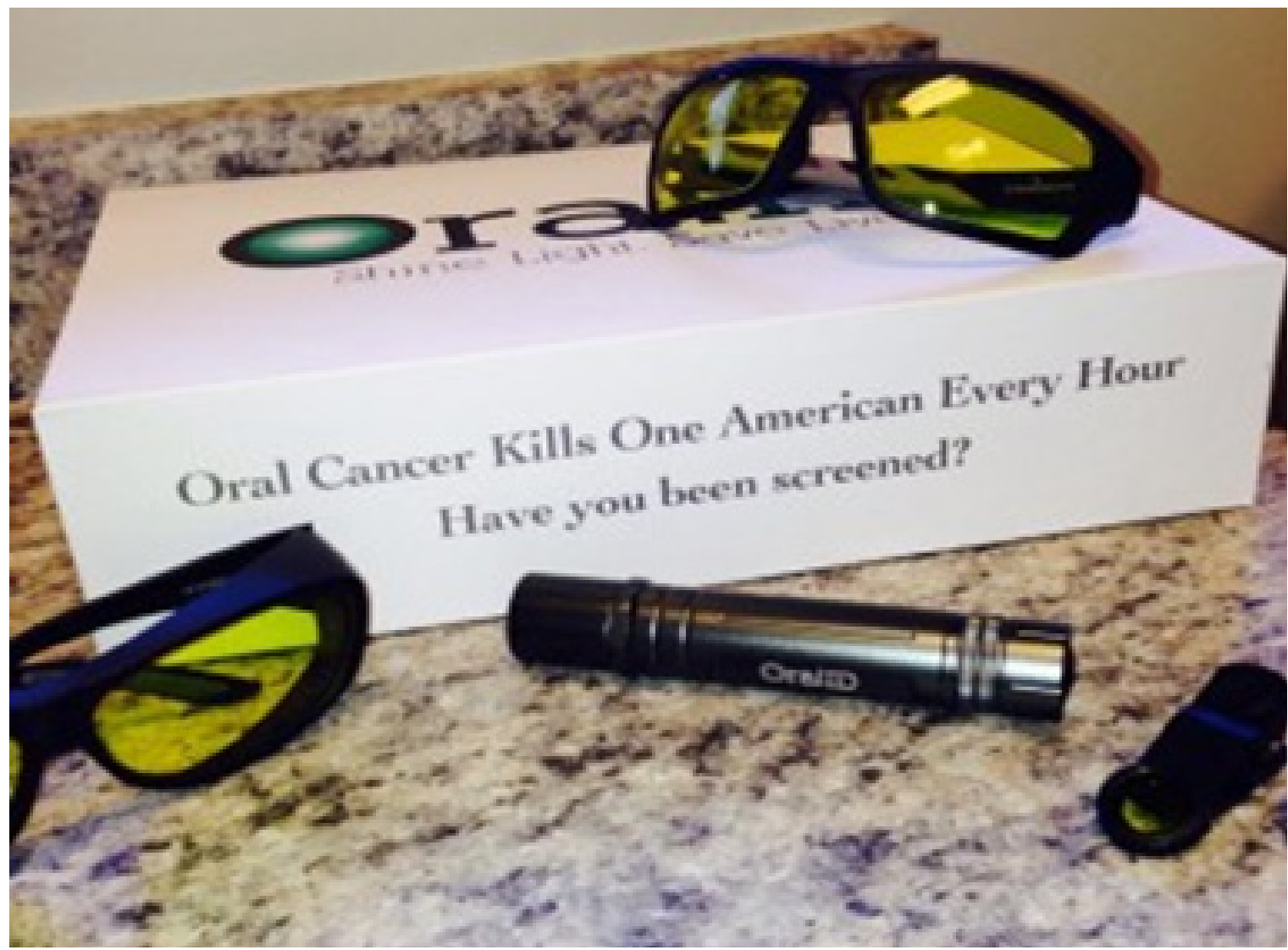

Fig. 1: A photograph showing the OralID * device OralID ${ }^{\text {TM }} 2.0$ (Forward Science Technologies, LLC, Stafford, TX) 


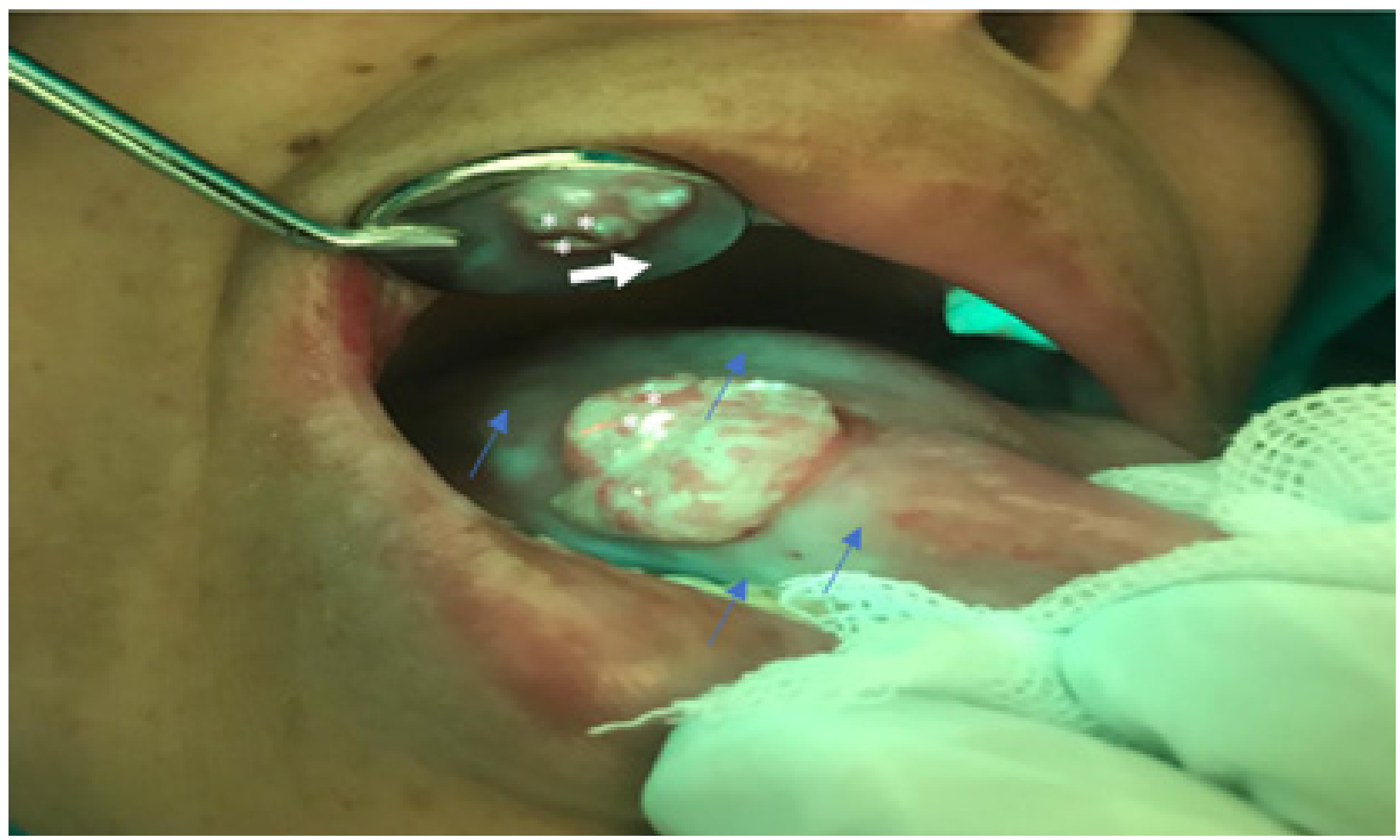

Fig. 2: Preoperative photograph case No. (6) with OralID device showing tongue lesion at right lateral border of tongue all areas around the lesion showing fluorescence. ( )

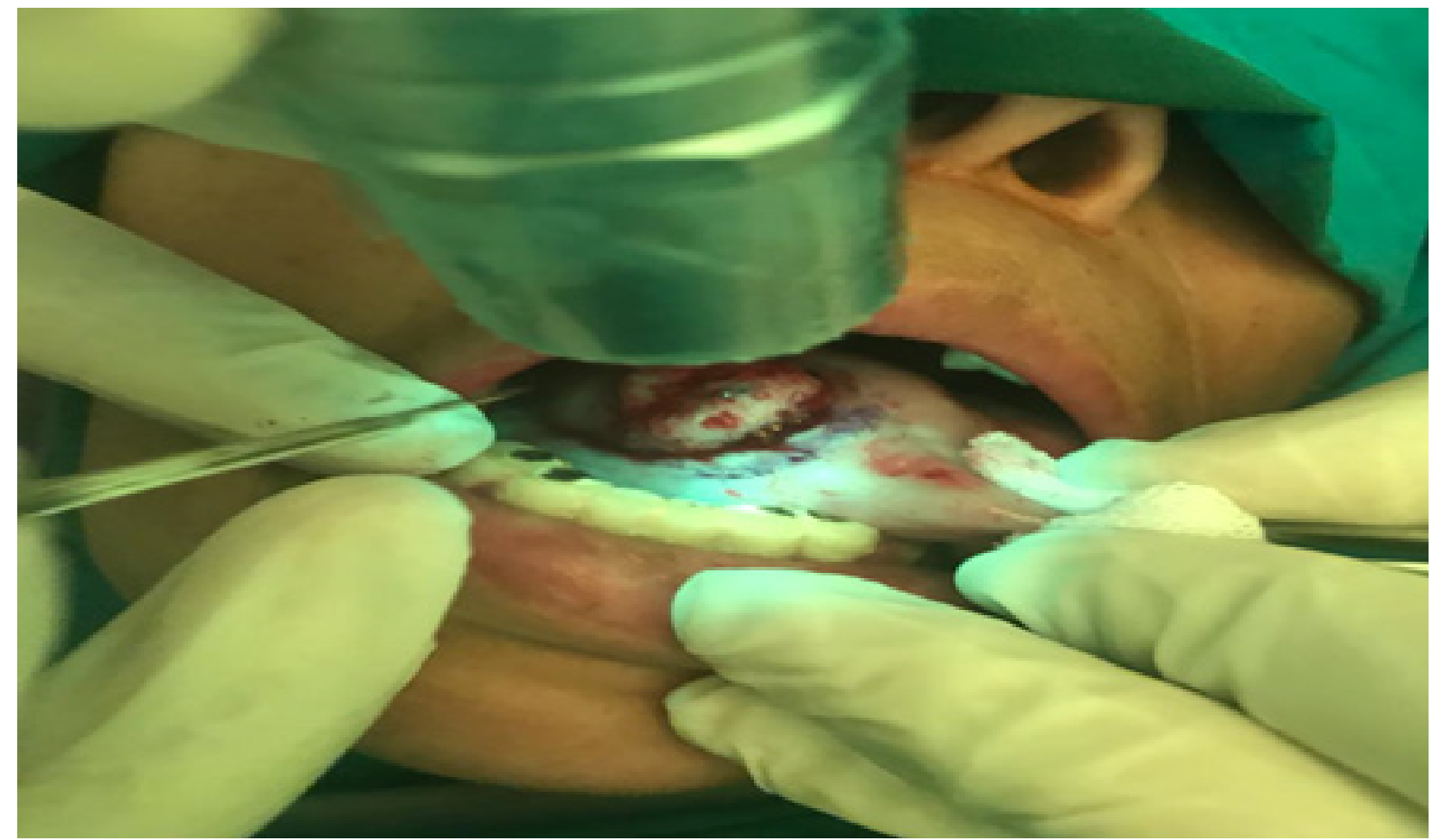

Fig. 3: Preoperative photograph case No. (6) showing: clinical line no (1) around exophytic white lesion at tongue and visual fluorescence boundary marking line no (2) at the beginning of the deepest green fluorescent and all areas around the lesion showed fluorescence. 


\section{RESULTS}

Twenty patients examined were found to have clinically abnormal areas of the mouth that persisted for 14 days after determination of specific medication or longer and after removal of the cause, these lesions were referred for surgical biopsy. All 20 patients included in the study underwent conventional oral examination and direct visual fluorescence examination (DVFE) with OralID.

Table (V-1): Determine distribution of patients age

\begin{tabular}{lcc}
\hline Age in years & Number $(\mathrm{n}=20)$ & $\%$ \\
\hline $20-$ & 1 & 5.0 \\
$30-$ & 4 & 20.0 \\
$40-$ & 4 & 20.0 \\
$50-$ & 4 & 20.0 \\
$60-70$ & 7 & 35.0 \\
Range & \multicolumn{2}{|c}{$20-70$} \\
Mean+SD & \multicolumn{3}{c}{$49.00+14.44$} \\
\hline
\end{tabular}

Table (V-2): Distribution of patient's sex

\begin{tabular}{lcc}
\hline Sex & Number $(\mathrm{n}=20)$ & $\%$ \\
\hline Males & 8 & 40.0 \\
Females & 12 & 60.0 \\
Total & 20 & 100.0 \\
\hline
\end{tabular}

Table 3: Determine the location of the lesions in the patients

\begin{tabular}{lcc}
\hline Location of lesion & Number $(\mathrm{n}=20)$ & $\%$ \\
\hline $\begin{array}{l}\text { Left lateral side } \\
\text { of tongue }\end{array}$ & 8 & 40.0 \\
$\begin{array}{l}\text { Right lateral } \\
\text { side of tongue }\end{array}$ & 6 & 30.0 \\
$\begin{array}{l}\text { Left alveolar ridge } \\
\begin{array}{l}\text { Lower alveolar } \\
\text { ridge }\end{array}\end{array}$ & 1 & 5.0 \\
$\begin{array}{l}\text { Right cheek } \\
\text { Left cheek }\end{array}$ & 2 & 5.0 \\
\hline
\end{tabular}

All biopsies were taken from the areas of the deepest fluorescent or fluorescent retained that meant a safety margin. The histopathologic examination determined that 6 patients had an inflammatory; 2 of these cases were diagnosed as lichenoid reaction cases No. $(10,13)$ and 2 cases were a traumatic ulcer No. $(2,12)$ and its periphery with normal epithelium and 2 patients No. $(9,11)$ had inflammatory ulcer but its periphery showed mild dysplasia, the OralID device was a good guidance for the safety margin as all tissues in areas surrounding the lesions and the lesion itself reflected a green fluorescence (Figures 4 and 5).

In 4 patients No $(3,4,16,18)$ after the histopathologic examination the lesion was squamous cell carcinoma and normal epithelium in all areas around the lesion with no dysplastic changes in these cases.

Another 4 patients No. $(5,7,14,20)$ revealed well differentiated squamous cell carcinoma and the lesion showed a loss in fluorescence. The histopathologic examination revealed the presence of malignant epithelial nests under the peripheral surface epithelium (Figures 6 and 7). 2 patients No. $(6,17)$ revealed squamous cell carcinoma after histopathologic examination and the periphery revealed mild dysplasia only in basal and para basal layer. 2 patients No. $(8,15)$ the fluorescent line aligned with the clinical line and after examination revealed invasive carcinoma with the periphery contained severe dysplasia (Figures 8 and 9).

Another 2 patients No. $(1,19)$ revealed carcinoma in situ and the periphery revealed severe dysplasia in these cases the periphery was in the green zone.

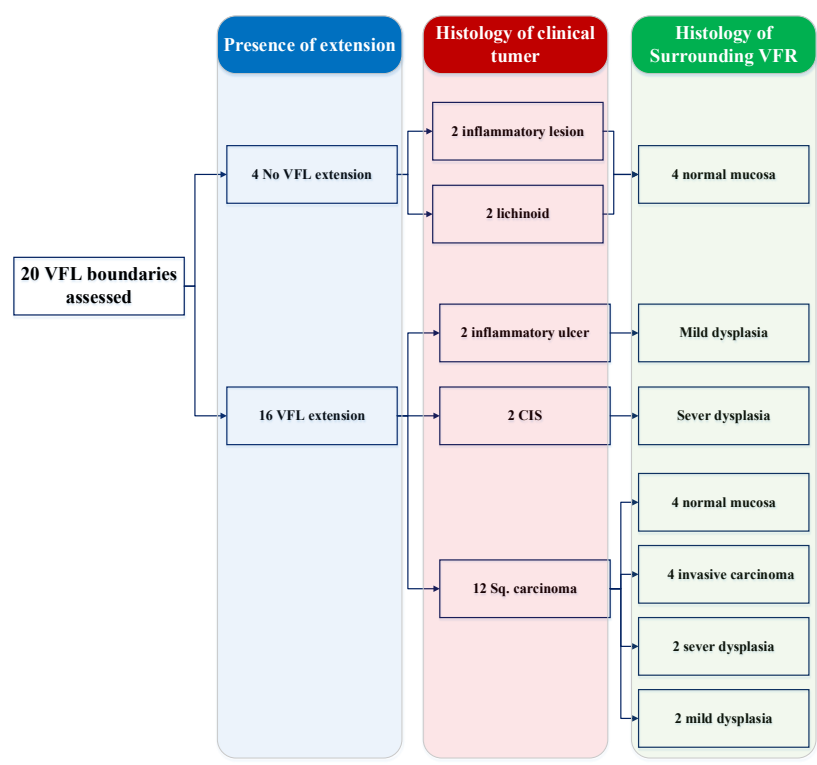

Assessment of VFL Boundary as true histologic margin

Table (V-4): Comparison of results of histopathology of biopsies with oral ID

\begin{tabular}{lcccc}
\hline \multirow{2}{*}{ Oral ID } & \multicolumn{4}{c}{ Histopathology } \\
& $\mathrm{N}$ & $\%$ & $\mathrm{~N}$ & $\%$ \\
\hline Positive & 20 & 100 & 12 & 60.0 \\
$\begin{array}{l}\text { Negative } \\
\begin{array}{l}\text { Detection } \\
\text { rate }\end{array}\end{array}$ & 0 & 0.0 & 8 & 40.0 \\
\hline
\end{tabular}

Sensitivity means the study results are positive when we test for positive that meant sensitivity $100 \%$ as the device showed fluorescent loss over the lesions and the areas around in 16 cases assured by histopathology and in the rest 4 cases it showed fluorescent retained over the lesions assured by histopathology as no dysplastic changes only inflammation that meant sensitivity $100 \%$. 
Specificity means the study results are negative when we test for negative as in all cases the device gave fluorescent retained in the areas around the lesion but with different grades that meant normal epithelium but after histopathological examination only 8 cases was taken with a safety fluorescent margin (negative results) and 4 cases were of mild dysplasia, 4 cases were sever dysplasia

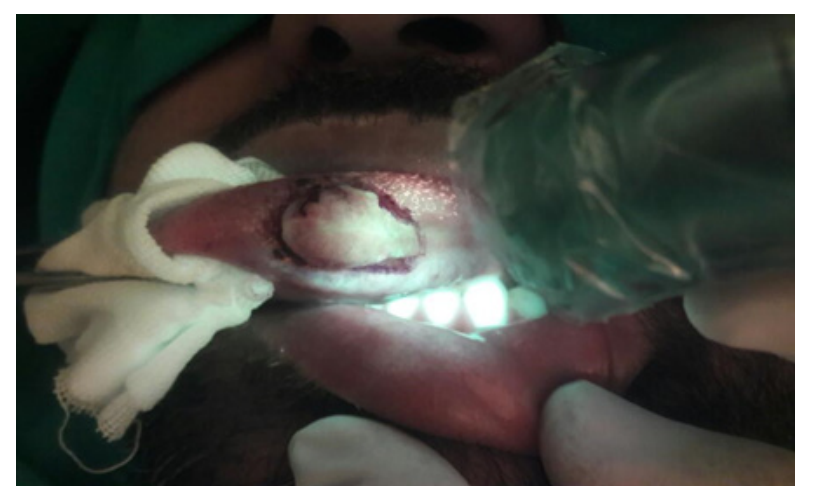

Fig. 4: Direct visual fluorescence examination (DVFE) and margin assessment case No. (2) of tongue in this case the fluorescence appeared all around the clinical margin and on the lesion itself so the clinical margin aligned with the OralID margin.

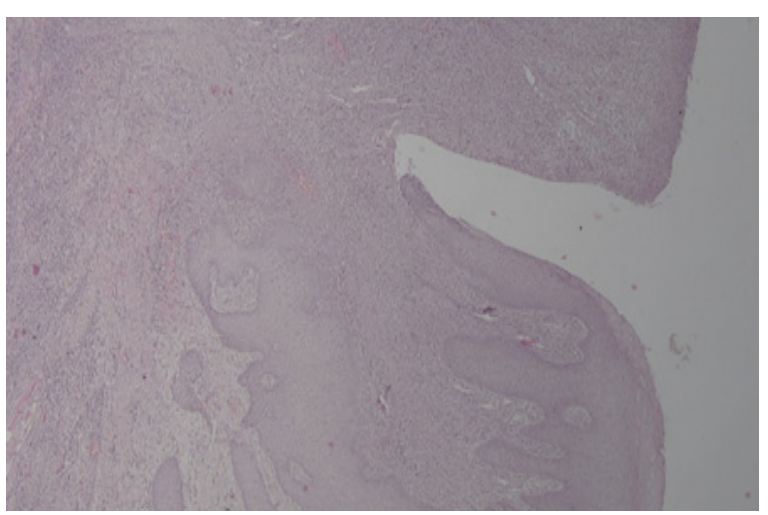

Fig. 5: Microscopic findings of the periphery of biopsy showed inflammatory reaction. The surface epithelium showed hyperplasia ( ) and the connective tissue infiltrated with chronic inflammatory cells. $(\Omega)$ $(\mathrm{H} \& \mathrm{E} \times 100)$.

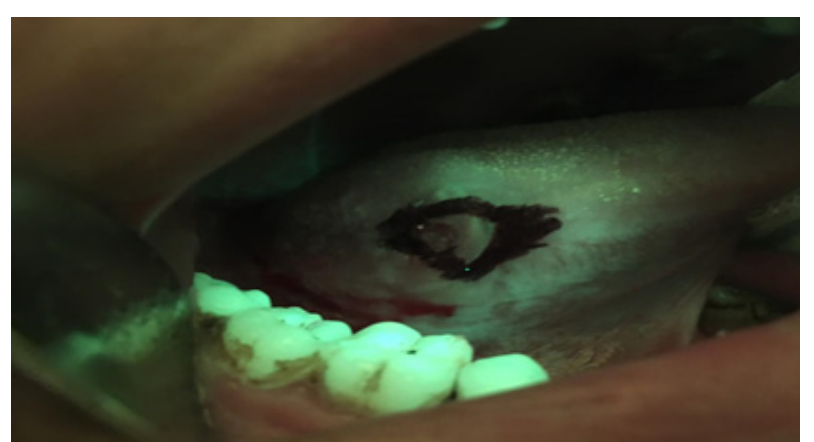

Fig. 6: A. DVFE and margin assessment of squamous cell carcinoma of tongue lesion case No. (14) line (1) around clinical margin and line (2) OralID margin the fluorescence appeared all around the clinical margin. and 4 cases showed invasive carcinoma (positive results). That meant specificity $40 \%$

The device gave fluorescent in all cases but only 8 cases from 20 biopsies had a safety margin so the device is not a good guidance in taking a biopsy but it will be more useful if used as initial diagnoses.

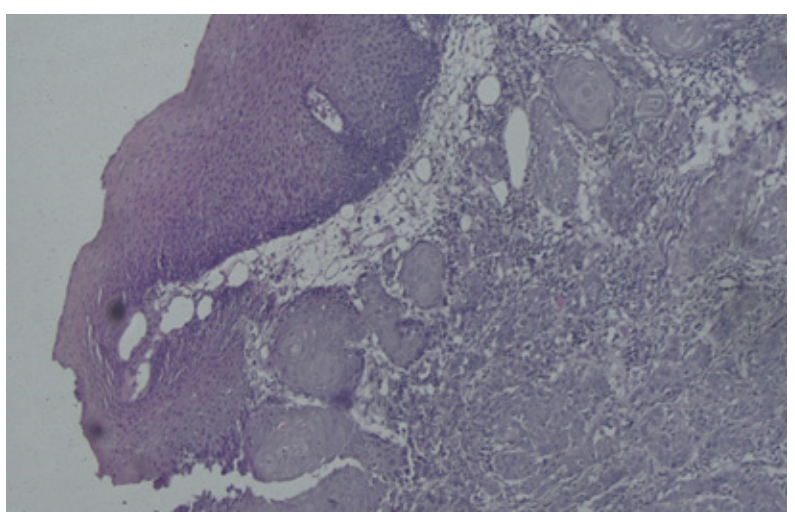

Fig. 7: B. Microscopic findings the periphery revealed nests of malignant cells ( $\checkmark$ ) invading the connective tissue under epithelium.

(H\&E x100)

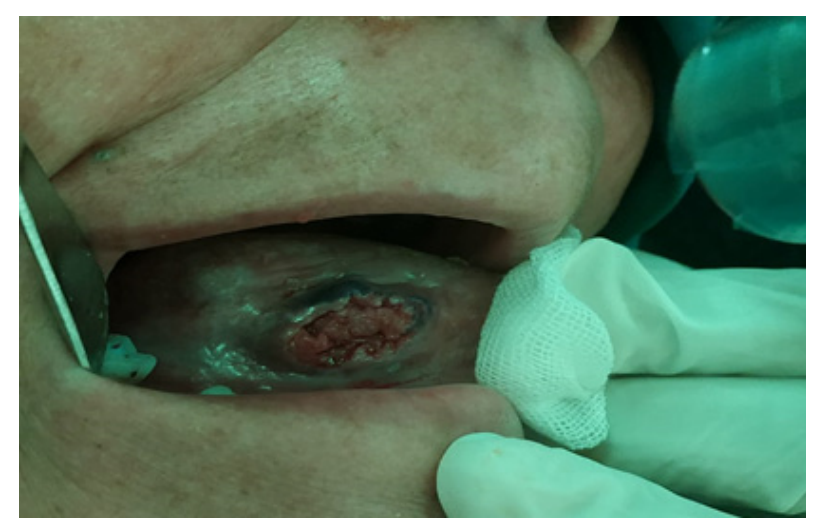

Fig. 8: A. DVFE and margin assessment of tongue lesion case No. (8) the fluorescent line aligned with the clinical line.

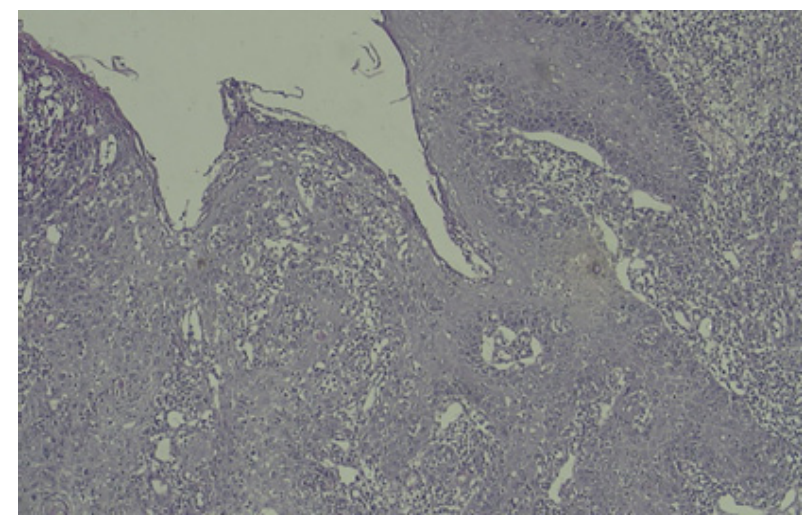

Fig. 9: B. Microscopic findings reveal invasion in connective tissue by malignant cells $(\uparrow)$ in periphery.

(H\&Ex100). 


\section{DISCUSSION}

In this study, we began the process of evaluating new approaches that can be easily used in clinical practice to facilitate the detection of these clinically occult fields ${ }^{[6,8]}$.

Previous authers have reported the development of a simple hand-held device that facilitated the detection of autofluorescence loss in both visible and occult high-risk oral lesions through direct fluorescence visualization ${ }^{[9,10]}$.

In our study, females exceeded males percentage, females $(60 \%)$, and this was in agreement with the studies achieved by (Chen et al., 1985) ${ }^{[1]}$ and (Silverman et al., 1998) ${ }^{[12]}$ who reported that the disparity in the male: female ratio has become less pronounced over the past half century, probably because women have been more equally exposing themselves to known oral carcinogens such as tobacco and alcohol.

Patients ages range from (20-70) years with mean 49+-14.44, and this was in agreement with the studies achieved by (Chen et al., 1985) ${ }^{[12]}$, (Llewellyn et al., 2001) ${ }^{[13]}$ and (Schatz et al., 2002) $)^{[14]}$ who reported that Oral cancer most commonly occurs in middle-aged and older individuals, although a disturbing number of these malignancies is also being documented in younger adults in recent years. This high incidence may be due to a strong correlation with chronic exposure to risk factors such as smoking and alcohol abuse.

In our study, there were 14 patients had the lesions in the lateral aspect of the tongue. Eight patients (40\%) had the lesions in left lateral side of tongue, six patients $(30 \%)$ in right lateral side of tongue, with the higher incidence to this area of the tongue and this was in agreement with the studies achieved by (Jovanovic et al., 1993) ${ }^{[15]}$ who reported that the lateral tongue and floor of mouth with extension back to the lateral aspect of the soft palate and tonsillar area combine to form a horse shoe shaped region of the oral mucosa, which is at greatest risk for cancer development and also they reported two major factors that may explain why this region is at high risk: first, any carcinogens will mix with saliva, pool in the bottom of the mouth, and constantly bath these sites; secondly, these regions of the mouth are covered by a thinner, nonkeratinized mucosa, which provides less protection against carcinogens.

In this study, normal mucosa emits green autofluorescence and in the pre-malignant and early cancers, the lesion presents itself as a dark area with different degrees of fluorescence loss or various shades of pale green. Our results showed that direct visual fluorescence examination is capable of identifying subclinical oral epithelial dysplasia extending beyond the clinically visible margin of oral SCC, this was in agreement with the studies achieved by (RichardKortum et al., 1996) ${ }^{[16]}$, (Ramanujam et al., 2000) ${ }^{[17]}$, (Gillenwater et al., 1998) ${ }^{[18]}$ who reported that morphologic alterations associated with epithelial neoplasia, including increased epithelial thickness, nuclear size, and micro vascularity, are considered responsible for the associated decreased autofluorescence seen with malignancy. It has also been suggested that decreased tissue fluorescence may reflect changes in metabolic activity associated with proliferating neoplastic cells.

In a study achieved by (Poh et al., 2007 $)^{[19]}$, the VELscope device was used as part of longitudinal follow up on patients following treatment for epithelial dysplasia or carcinoma in situ (CIS). Investigators performed a conventional oral examination followed by a fluorescent examination and reported three cases in which clinically non-evident lesions were identified using the VELscope: moderate epithelial dysplasia, second primary CIS, and recurrent CIS. These examples demonstrate a potential value of the device in identifying occult lesions that would otherwise go undetected by conventional oral examination.

For those clinicians in general practice without the experience and expertise of a specialist, an imaging device to aid in the decision to refer would be very helpful. At the community level, the critical decision is not whether or not the lesion is cancer but whether or not the lesion should be referred for further investigation.

\section{CONCLUSION}

From our study, we concluded that: the current study is an important step in the development of a potential integration of optical technology into the management of patients with oral cancer. Direct visual fluorescence examination shows promise in tumor margin delineation during surgical management of patients with oral cancer and precancer, however, the false negative test results may limit its utility in controlling a biopsy margin but in routine screening of the oral cavity its sensitivity is $100 \%$.

There are also technical challenges of direct visual fluorescence examination were related to tumor size and location, room light, the clinical examination is subjective and varies with the experience of the clinician and angulation of the OralID.

\section{RECOMMENDATION}

OralID device is recommended as a diagnostic too as its sensitivity is $100 \%$ so it will be helpful in initial diagnosis of lesions that can't be seen with naked eyes. But it can't be helpful in controlling a biopsy margin with a safety margin as its specificity is $40 \%$.

Technical challenges related to the degrees of light that could not be analyzed by naked eyes as we found different degrees of fluorescent green light so it may need to get the biopsy with more wide safety margin or analyze these different grades of green by photo analyses programs. 


\section{CONFLICT OF INTEREST}

There are no conflicts of interests.

\section{REFERENCES}

1. Sankaranarayanan R, Ramadas K, Thomas G, Muwonge R, Thara S, Mathew B, et al.,: Effect of screening on oral cancer mortality in Kerala, India: a cluster-randomised controlled trial. Lancet. 2005 Jun 4;365(9475):1927-33. (2005)

2. Nair D, Pruthy R, Pawar U et al.,: Oral cancer: premalignant conditions and screening- an update. J Can Res Therap 2012; 8 (Suppl 1): s57-s66. (2012)

3. Panjwani S, Sadiq S.: p53 expression in benign, dysplastic and malignant oral squamous epithelial lesions. Pak J Med Sci 2008;24:130-5. (2008)

4. Lumerman H, Freedman P, Kerpel S.: Oral epithelial dysplasia and the development of invasive squamous cell carcinoma. Oral Surg Oral Med Oral Pathol Oral Radiol Endod 1995;79:321-9. (1995)

5. Ramanujam N, Mitchell MF, Mahadevan $\mathrm{A}$, et al.,: In vivo diagnosis of cervical intraepithelial neoplasia using 337-nm-excited laser-induced fluorescence. Proc Natl Acad Sci U S A 1994;91: $10193 \wedge$ ^ . (1994)

6. Ingrams $\mathrm{DR}$, Dhingra $\mathrm{JK}$, Roy $\mathrm{K}$, et al., Autofluorescence characteristics of oral mucosa. Head Neck 1997;19:27^ 32. (1997)

7. Saini R.: Oral Cancer Screening in Dental Set Up. International Jornal of Biomedical and Advance Research;6(3):199-203. (2015).

8. Lam S, M acAulay C, Hung J, LeRiche J, Profio AE, Palcic B.: Detection of dysplasia and carcinoma in situ with a lung imaging fluorescence endoscope device. J Thorac Cardiovasc Surg $1993 ; 105: 1035 \wedge 40 .(1993)$

9. Lane PM, Gilhuly $\mathrm{T}$, Whitehead $\mathrm{P}$, Zeng $\mathrm{H}$, Poh CF, Ng S, et al.,: Simple device for the direct visualization of oral-cavity tissue fluorescence. JBiomedOpt. 2006;11:024006. doi:10.1117/1.2193157. PubMed PMID: 16674196. [PubMed]. (2006)
10. Poh CF, Ng SP, Williams PM, et al.: Direct Fluorescence visualization of clinically occult high-risk oral premalignant disease using a simple hand-held device. Head Neck 2006 Sept. 18 online publication. (2006)

11. Chen JK, Katz RV, Krutchkoff DJ: Intraoral squamous cell carcinoma. Epidemiologic patterns in Connecticut from 1935 to 1985. Cancer 1990;66:1288-1296. (1985)

12. Silverman S Jr: Epidemiology. In: Silverman S Jr ed. Oral Cancer. 4th ed. Hamilton, Ontario, Canada: BC Decker Inc;1998;1-6.(1998)

13. Llewellyn CD, Johnson NW, Warnakulasuriya KA: Risk factors for squamous cell carcinoma of the oral cavity in young people-a comprehensive literature review. Oral Oncol 2001;37:401- 418 . (2001)

14. Schantz SP,Yu GP: Head and neck cancer incidence trends in young Americans, 19731997, with a special analysis for tongue cancer. Arch Otolaryngol Head Neck Surg 2002;128:268- 274. (2002)

15. Jovanovic A, Schulten EA, Kostense PJ et al., Tobacco and alcohol related to the anatomical site of oral squamous cell carcinoma. J Oral Pathol Med 1993;22:459-462. (1993)

16. Richards-Kortum R, Sevick-Muraca E. Quantitative optical spectroscopy for tissue diagnosis. Annu Rev Phys Chem 47:555-606.( 1996)

17. Ramanujam N. Fluorescence spectroscopy of neoplastic and non-neoplastic tissues. Neoplasia 2:89-117. 48.(2000)

18. Gillenwater A, Jacob R, Ganeshappa R, Kemp B, El-Naggar AK, Palmer JL, Clayman G, Mitchell MF, Richards-Kortum R. Noninvasive diagnosis of oral neoplasia based on fluorescence spectroscopy and native tissue autofluorescence. Arch Otolaryngol Head Neck Surg 124:1251-1258. (1998)

19. Poh CF, Ng SP, Williams PM, Zhang L, Laronde DM, Lane P, Macaulay C, Rosin MP. Direct fluorescence visualization of clinically occult high-risk oral premalignant disease using a simple hand-held device. Head Neck; 29:71-76. (2007) 